\title{
Lung Cancer pT4 TNM Finding v6
}

National Cancer Institute

\section{Source}

National Cancer Institute. Lung Cancer pT 4 TNM Finding v6. NCI Thesaurus. Code C60971.

Lung cancer with invasion of the mediastinum, heart, great vessels, trachea, esophagus, vertebral body or carina, or presence of separate tumor nodules within a same lobe, or the presence of a malignant pleural effusion. Although most pleural effusions associated with lung cancer are due to tumor, there are a few patients in whom multiple cytopathologic examinations of the pleural fluid are negative for tumor. In these cases, the fluid is non-bloody and is not an exudate. Such patients may be further evaluated with videothoracoscopy and direct pleural biopsy. When these elements and clinical judgment dictate that the effusion is not related to the tumor, the effusion should be excluded as a staging element. (from AJCC 6th Ed.) 